\title{
Ozone Desulfurization And Denitrification System Modeling Based On UML
}

\author{
Mei Lin ${ }^{1, ~ a ~}$, Baocheng Lu ${ }^{2, b}$ and Kai Zhang ${ }^{3, c}$ \\ 1.2 Binzhou Polytechnic No.919, Huanghe 12 Road,Binzhou, Shandong Province \\ ${ }^{3}$ SHANDONG BEFAR BINYANG FUEL CHEMICAL CO.,LTD Binzhou, Shandong Province \\ aLinq_0324@163.com, b176816963@qq.com, 'bygczk@163.com
}

\begin{abstract}
UML, an important tool of OOA, is a standard modeling language which has been widely used by public. It not only can provide a graphic modeling language way to design software, but also be used in the whole system developing lifecycle. Via UML modeling promises higher software development efficiency, better software quality, and less maintence expenses. Under the background of development desulfurization and denitrification system. This paper aims at the research of UML modeling and the combination of PLC and UML technology together. The combination of UML modeling language not only improve the efficiently of system development, but also is beneficial to the development and maintenance of system later.
\end{abstract}

Keywords: UML Modeling, Desulfurization, Denitrificaiton, PLC.

\section{Introduction}

Unified Modeling Language, or UML for short, as the standard object-oriented modeling language, has been widely used in complex systems and application software. Its emergence provide a visualization and standardization of support for all stages of software development.UML modeling can make designing process simpler and make a "blueprint” for the system. Through a set of highly expressive containing different graphical elements of the graph to express the system structure, behavior and characteristics. Due to its advantages, UML are used gradually for object analyzing and desi designing in modem software engineering now.

Along with the coming of 4.0 industrial era, the uses of automatic control system are widespread in the production of modern large industry and as the main part of the system, Programmable Logic Controller(PLC) is used widely too.PLC realize the modularization design, standardization design and reuse design of system. But the way of PLC software programming often depend on developer's experience, which will lack of a uniform standard. This problem is particularly acute in complex process industrial. Design ideas cannot effective show by PLC.

Based on this, using UML to realize the visual modeling of PLC program is particularly necessary.

\section{The feasibility of UML modeling}

Ozone desulfurization and denitrification system is a kind of energy saving and flue gas emission reducing system. The data stream in the system data channels in clouding data transfer, dataprocessing, data store and data interaction with users is the core control. How the adaptive control of flue gas flow is the key to affect the discharge gas content standard quality.PLC has high reliability, convenient and flexible program design, strong anti-interference ability, stable operation. So the desulfurization denigration controller widely used PLC as the control unit. In order to make the PLC control system can better adapt to the adjustment of flue gas change, we introduce the UML modeling to control process modeling, UML modeling can be divided into the static modeling and dynamic modeling. Among them, the basis of system modeling is the static modeling including: a use case diagram, class diagram, object diagram, package diagram, component diagram and configuration diagram and dynamic modeling include: news state diagram, sequence diagram collaboration diagram and activity diagram. Owing to its particular emphases, these 
modeliare divided into five categories During the modeling, developer can do this with the flexibility of using these modeling diagrams. Associated with ozone desulfurization and denitrification system, this pager choose case diagram, sequence diagram, activity diagram to build PLC control model.

The performance of the software must be improve by UML modeling and it is benefit for maintenance and controlling of soft cost in the evening of project.

Functional Analysis

Ozone desulfurization and denitrification system sharply reduce exhausted missions. More importantly, it will reduce baleful gas in this process. This system consists of six modules:ozone generating module, denitration circulation module, sodium alkali module, automatic alarm module and liquid precipitation module. This technology realize by the control system.

The process in accordance with the "standard of boiler air pollutant emissions in shandong province" in 2015 emission concentration limit standard, realize the energy conservation and emissions reduction, to achieve enterprise's normal production. The realization of the control system first need to determine the requirements of the control system, used the phase main job is to determine the user of the system and their business activities.

function module

Ozone generating module using high-frequency Parallel Plates Dielectric Barrier Discharge creates ozone-saturated bubbles, then ozone fully mix with gases by jet nozzle. Through these pathways,we will realize NO fully, rapid oxidation, meet in relatively high concentrations of NOX removal efficiency.

Denitration Circulation Module mainly consists of a oxidation unit, lye Circulation pumps, $\mathrm{pH}$ automatic controller, liquid level switches.

Sodium Alkali Module: desulfurized grout must add the fitting quantity and kind of additive. For this reason, this module need a reservoir, a Powder storehouse and pump to provide enough additive which can absorb nitrous oxides .

Chemical Dosing Control Module: When the alkali liquor preparation tank PH value is less than 10, feeding machine manually add Sodium hydroxide potion and Electromagnetic valve automatically open filling water at the same time.

When $\mathrm{PH}$ value is less than 8 in the tank, $\mathrm{pH}$ automatic controller will transmit signals to lye Circulation pumps that transferring appropriate concentration of lye for the denitration system.

Automatic Alarm Module: indicate that the current detection system more than standard value, the need for human intervention.

A human-machine interface module:in order to ensure the normal operation of equipment, Operators can run according to the visual interface of real-time testing and manual intervention,as follow in Fig. 1. 


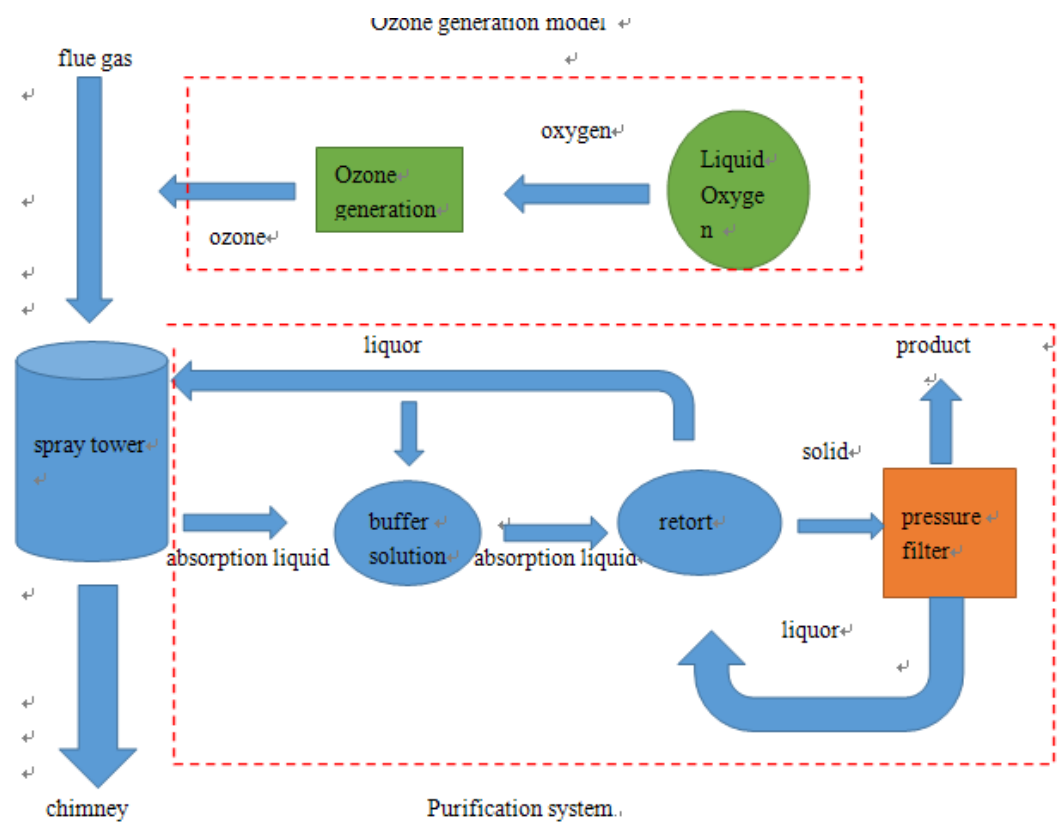

Fig.1 Function module

Use-case diagram design

Use case diagram is mainly composed of a set of system use-case,use case executor and correspondence relationship.Each system usa case will manipulate some entities,and the entities are usually involved in multiple system use cases.

For ozone desulfurization and denitrification system,the primary actors are operating user and maintainer.

Operating user can perform the following operation:system startup or stop,flue gas state-monitoring, emission control and drug information.

Maintainer take charge of the operation of the whole system and ensure the operation safety,such as: PLC Program Manager, sensor signals control, maintenance and management of hardware, communication manager, database upgrading, Man-machine Interface maintenance .

When determining actors and use case of system, we can draw top level use case diagram show as Fig.2.

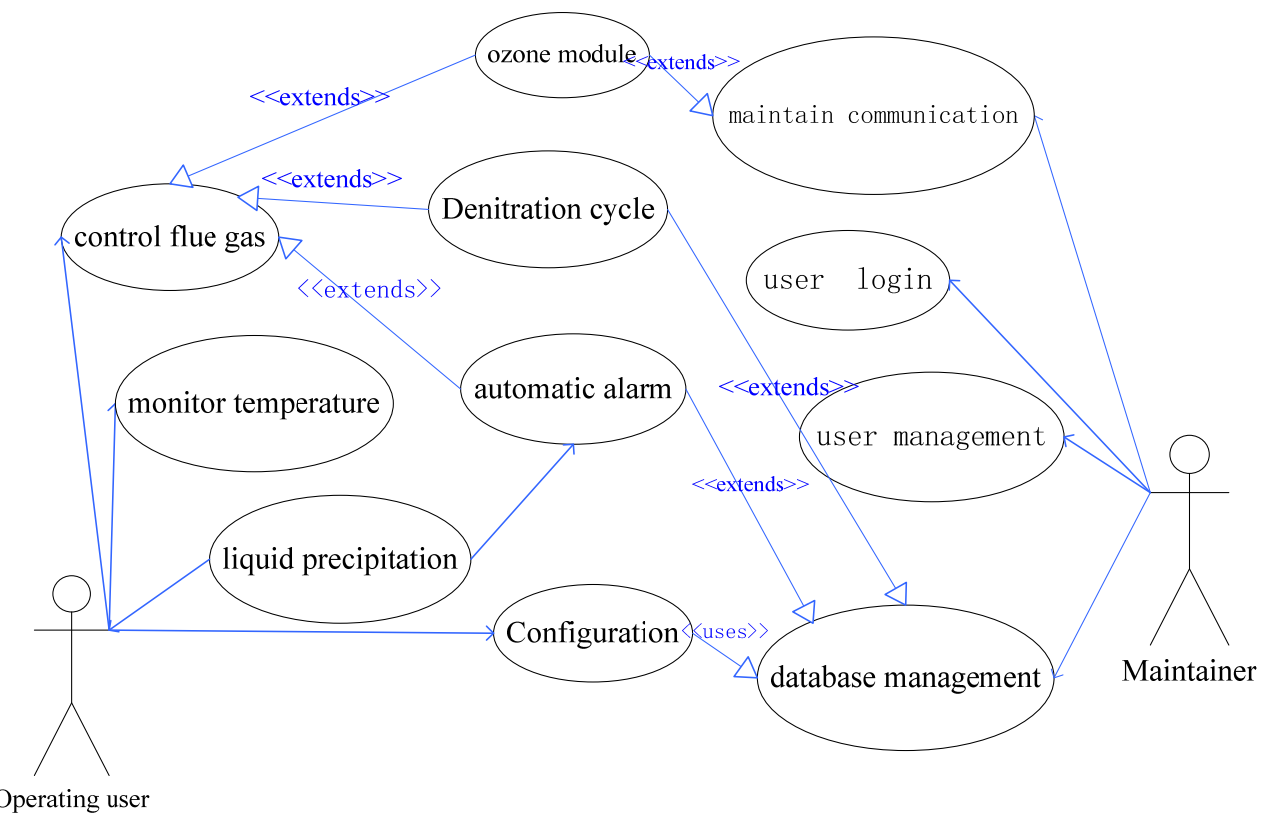

Fig.2 Draw top level use case 
You can see from top level use case diagram that many use case remains abstract such as denitration cycle case, sodium alkali case, database management case and so on. In order to express more clearly design thought, these cases that may call for further refinements. For brevity,this paper only refines denitration cycle case, other cases of refinement no longer in detail.

Denitration cycle cases of refinement

According to the denitration process, the flue gas enters the denitration tower and spray the lye to it. NO2 from the flue gas will react with lye. By chemical absorption, it will drains off into the pool. In this way, the flue gas could achieve the purpose of removing Nox. Finally, Flue gas passes through the built-in cyclone dewatering device into the public flue. By the function of process description, denitration circulation use cases can be further refined for flue gas oxidation treatment cases, lye atomization cases, liquid level, liquid level control cases, test cases PH test cases, communication, PLC signal detection use cases. Use case diagram as shown in Fig3.

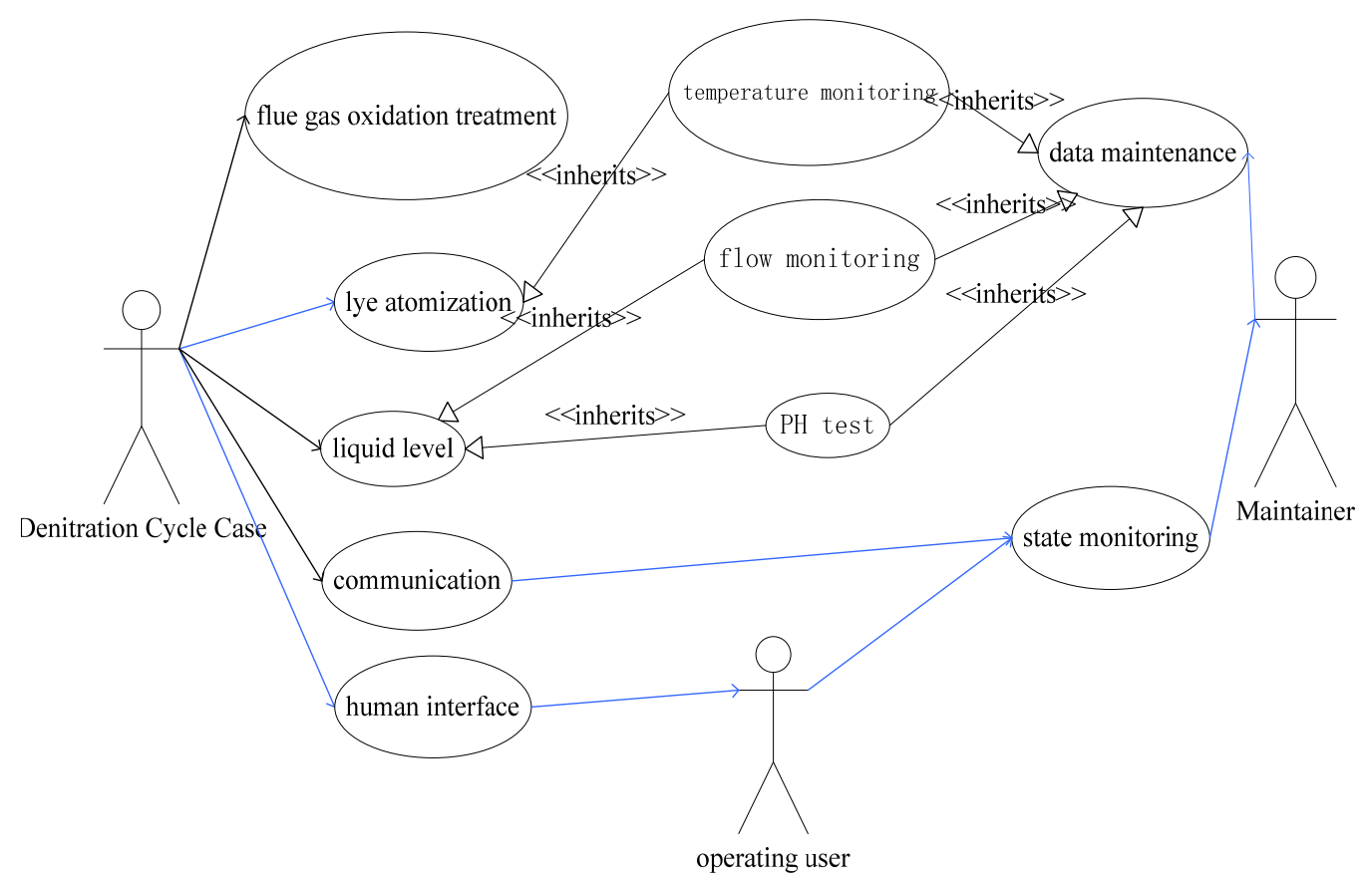

Fig.3 Denitration cycle cases

Configuration management refinement

Through kingview software, a operating user realize the visualized operation and control of PLC in detail and real-time monitoring of exhaust gas. By the function of process description, Configuration management cases can be further refined for configuration user cases, configuration information input cases, configuration information output cases, database use cases, information monitor cases, Information transmission cases, PID control cases. Use case diagram as shown in Fig 4. 


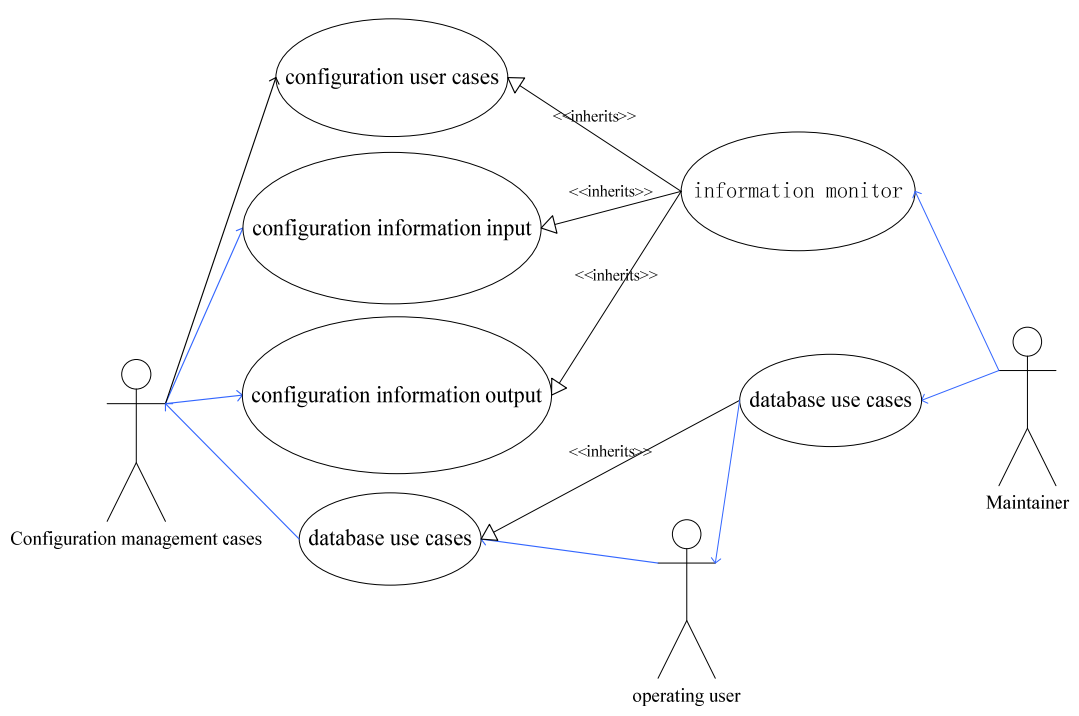

Fig.4 Configuration management cases

\section{State Transition Diagram}

Among various modules in the system often need to interact with each other, using UML state transition diagram can be a good description of the working state and state transition in the system and can be very good to the late PLC software programming services. Considering the control system based on PID algorithm and program sequence control, the control system of ozone desulfurization denitration state diagram as shown in Fig.5.

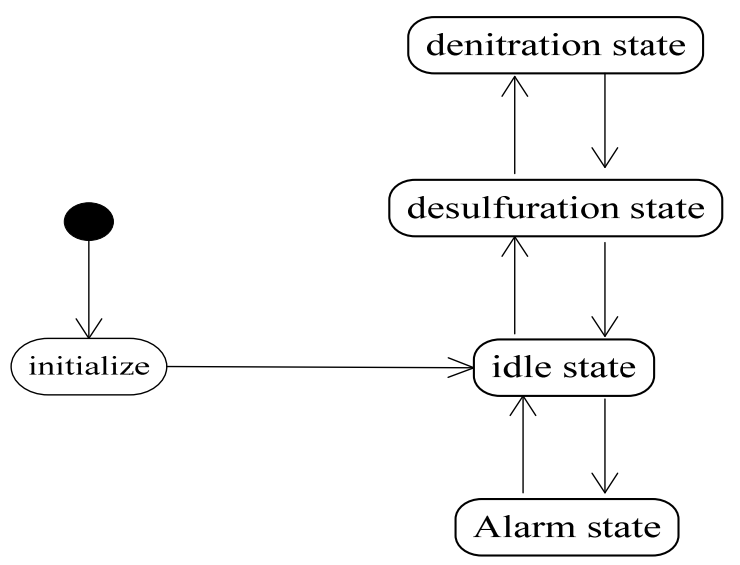

Fig.5 State Transition Diagram

The transformation of the idle state to desulfurization state is as follows: in the flue gas flow, $\mathrm{PH}$ value is less than 7, flue gas desulfurization call button is pressed or denitration equipment is requested. Desulfurization state to the denitration state transformation is as follows: the condition of complete all desulfurization task, namely the $\mathrm{PH}$ value is greater than 7 , flue gas after sulfur absorption tower of liquid flows out of stock, sold out of tower equipment. The conditions of the free state to the alarm state transformation is as follows: equipment failure at the request of the alarm button is pressed, the flue gas excess real-time monitoring.

Configuration of the state of the refinement 


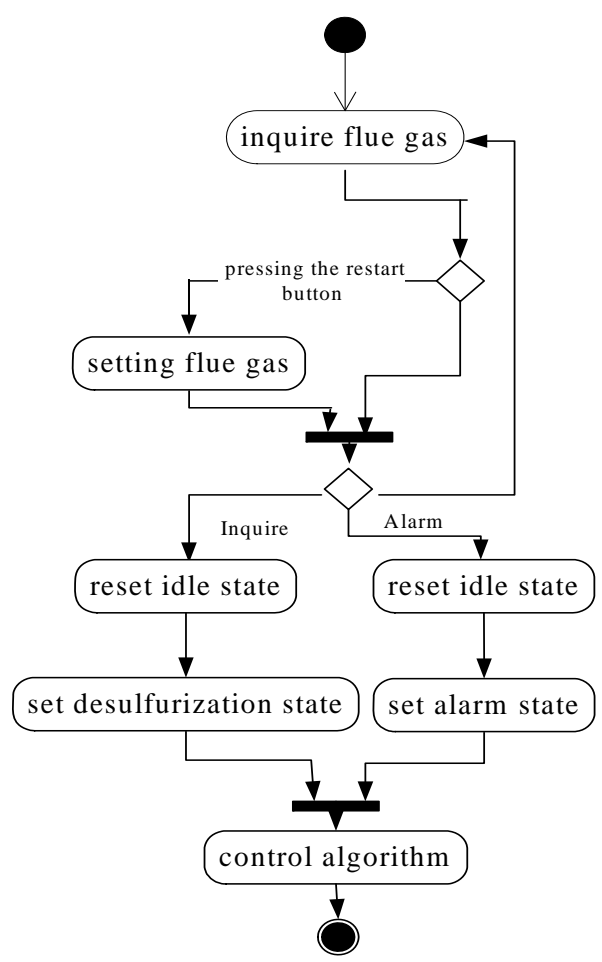

Fig 6 Configuration of the state of the refinement

\section{PLC design}

PLC software programming provides a sequential language programming environment to users.which can realize the state of the system transformation. So SFC consistent with the UML modeling idea. Specific content as follows :it divide the big task into several small tasks. The small tasks is called step by PLC and is called state in UML modling,Conversion between each step needs specific conditions. According to the thought of the software engineering, uml modeling and PLC software programming can efficiently combine. using step7 software to achieve its main program programming.

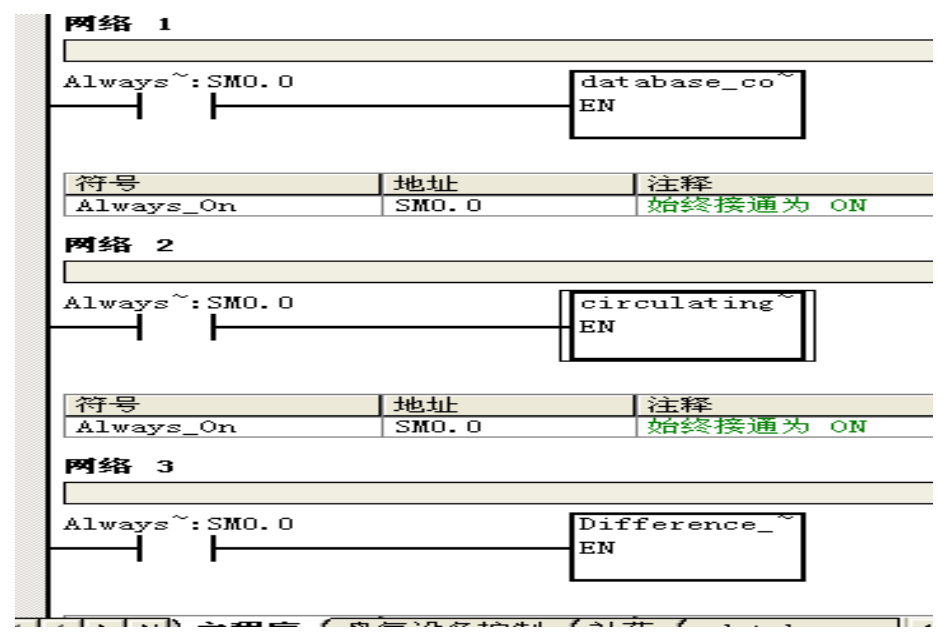

Fig.7 PLC programme 


\section{References}

[1] Michael F Z, Clemens P. Model-driven Development of PLC Software for Machine Tools[J]. Production Engineering, 2014, 2(1): 39-46.

[2] Georg F, Lothar L. Formal Methods in PLC Programming[C]//Proc. of the IEEE Conference on SMC. Nashville, TN, USA: [s. n.], 2015. 